\title{
Study of Tamoxifen and Raloxifene
}

National Cancer Institute

\section{Source}

National Cancer Institute. Study of Tamoxifen and Raloxifene. NCI Thesaurus. Code C16110.

Part of the National Surgical Adjuvant Breast and Bowel Project. A study to compare the efficacy of Tamoxifen to Raloxifene in prevention of primary breast cancer among women at high risk for the disease. 